\title{
Surgical Outcomes and Complications Following All Posterior Approach for Spinal Deformity Associated with Neurofibromatosis Type-1
}

\author{
Byoung-Joo Park, Seung-Jae Hyun, Seong-Hyun Wui, Jong-Myung Jung, Ki-Jeong Kim, Tae-Ahn Jahng \\ Department of Neurosurgery, Spine Center, Seoul National University Bundang Hospital, Seoul National University College of Medicine, \\ Seongnam, Korea
}

Objectives : The purpose of this study was to evaluate surgical outcomes and complications of spinal deformity associated with neurofibromatosis type-1 (NF-1).

Methods : From 2012 to 2018, patients suffering from spinal deformity associated with NF-1 who underwent surgical correction were identified. Demographic data and radiographic measures were retrospectively reviewed. Pre- and postoperative whole spine radiograph images were used to determine both coronal and sagittal Cobb angles. All of patients underwent 3-dimentional computed tomographic scan and magnetic resonance imaging scan to confirm dystrophic features. For evaluation of clinical outcomes, we surveyed the pre- and postoperative scoliosis research society-22r (SRS-22r) score.

Results : Seven patients with spinal deformity associated with NF-1 were enrolled in this study. The mean age of patients was $29.5 \pm 1.2$ years old. The mean follow-up period was $2.8 \pm 1.4$ years. The apex of the deformity was located in cervicothoracic $(n=1)$, thoracic $(n=4)$, and lumbar region $(n=2)$. Most patients have poor bone quality and decreased bone mineral density with average T-score of $-3.5 \pm 1.0$. All patients underwent surgical correction via posterior approach. The pre- and postoperative mean coronal and sagittal Cobb angle was $61.6 \pm 22.6^{\circ}$ and $34.6 \pm 38.1^{\circ}, 56.8 \pm 18.5^{\circ}$ and $40.2 \pm 9.1^{\circ}$, respectively. Mean correction rate of coronal and sagittal angle was $44.7 \%$ and $23.1 \%$. Ultimate follow-up SRS-22r score (average score, 3.9 \pm 0.4 ) improved comparing to preoperative score (average score, $3.3 \pm 0.9$ ). Only one patient received revision surgery due to rod fracture. No serious complication occurred, such as neurological deficit, and viscerovascular injury.

Conclusion : The surgical correction of patients having spinal deformity associated with NF-1 is challenging, however the radiographic and clinical outcomes are satisfactory. The all posterior approach can be a safe and effective surgical option for patients having dystrophic curves associated with NF-1.

Key Words : Neurofibromatosis $1 \cdot$ Scoliosis · Kyphosis · Surgical procedures · Complication · Instrumentation.

- Received : October 31, 2019 •Revised : January 5, 2020 •Accepted : February 19, 2020

- Address for reprints : Seung-Jae Hyun

Department of Neurosurgery, Spine Center, Seoul National University Bundang Hospital, Seoul National University College of Medicine, 82 Gumi-ro 173beon-gil, Bundang-gu, Seongnam 13620, Korea

Tel : +82-31-787-7169, Fax : +82-31-787-4097, E-mail : hyunsj@snu.ac.kr, ORCID : https://orcid.org/0000-0003-2937-5300

This is an Open Access article distributed under the terms of the Creative Commons Attribution Non-Commercial License (http://creativecommons.org/licenses/by-nc/4.0) which permits unrestricted non-commercial use, distribution, and reproduction in any medium, provided the original work is properly cited. 


\section{INTRODUCTION}

Neurofibromatosis type-1 (NF-1), von Reckling-hausen disease, peripheral neurofibromatosis is a rare autosomal dominant hereditary disorder. This disease is characterized by multiple cutaneous neurofibromas, multiple café au lait macules, axillary and inguinal freckle, iris Lisch, and choroidal freck$\operatorname{ling}^{30)}$.

About 50\% of patients with NF-1, have orthopedic disorders $^{30)}$. Orthopedic complications appear as either focal or generalized features ${ }^{5}$. Focal orthopedic complications include long bone or sphenoid wing dysplasia, chest wall deformity and short segmented scoliosis. Generalized feature include short stature, larger head circumference, and decreased bone mineral density $(\mathrm{BMD})^{17)}$. Most common skeletal manifestation is spinal deformity ${ }^{30)}$. Scoliosis of NF-1 patients is accounted about 3\% of all scoliosis cases ${ }^{23)}$. Usually, Scoliosis associated with NF-1 is classified into nondystrophic and dystrophic type $e^{21,30)}$.

Clinical radiographic findings and treatment of nondystrophic type are very similar to those of idiopathic scoliosis ${ }^{21,24,30)}$. Furthermore, NF-1 patients with nondystrophic type scoliosis appear earlier in life than idiopathic scoliosis. And they have a worse prognosis and more complications after correction surgery such as pseudarthrosis or fusion failure ${ }^{2,12}$. Typical features of Dystrophic type scoliosis include wedging of vertebral body, vertebral scalloping, spindling of transverse process, rib penciling, paraspinal or intraspinal soft tissue mass, dural ectasia and sharp angular curves ${ }^{21,28)}$. Previous researcher reported that 3 or more dystrophic features is highly predictive of curve progression and the need for surgery ${ }^{17)}$.

Occasionally deformity correction surgery is required due to curve progression or severe spinal deformation in NF-1 patients with spinal deformity. The surgical correction of patients having spinal deformity associated with NF-1 is challenging. The purpose of this study was to evaluate surgical outcomes and complications of spinal deformity associated with NF-1.

\section{MATERIALS AND METHODS}

This study was obtained approval of the Ethics Commitee and Institutional Review Board of Seoul National University
Bundang Hospital before initiation of the study (IRB No. B-1910-572-105). We reviewed scoliosis patients who meet diagnostic criteria of NF-1 from 2012 to 2018. A diagnosis of NF-1 was based on the criteria showed in Table $1^{34)}$. Among them, patients who underwent surgical correction were identified. Demographic data and radiographic measures were retrospectively reviewed. In addition, the demographic characteristic of patients including age, sex, follow-up period, history of previous surgeries was collected and recorded.

Table 1. Diagnostic criteria defined by the 1987 Consensus Development Conference of National Institutes of Health for the diagnosis of neurofibromatosis. Two or more criteria present confirm the diagnosis of NF-1

Diagnostic criteria for NF-1
Six or more café-au-lait macules $>5 \mathrm{~mm}$ in greatest diameter in pre-
pubertal individuals and $>15 \mathrm{~mm}$ in greatest diameter in post-
pubertal individuals
Two or more neurofibromas of any or more than one plexiform
neurofibroma
Freckling in the axillary or inguinal regions
Optic glioma
Two or more Lisch nodules (iris hamartomas) by slit lamp examination
A distinctive osseous lesion, such as sphenoid dysplasia or thinning
of a long bone cortex, with or without pseudarthrosis
A first-degree relative (parent, sibling, or offspring)

NF-1 : neurofibromatosis type-1

Table 2. Typical dysplastic change evident on plain radiographs in patients with NF-1

\section{Dysplastic change}

Vertebral scalloping (considered to be present when the depth of scalloping is more than three millimeters in the thoracic spine or more than four millimeters in the lumbar spine)- this is either associated with dural ectasia or neural tumour

Rib pencilling (considered to be present when the width of the rib was smaller than that of the narrowest portion of the second rib)

Transverse process spindling

Vertebral wedging

Paravertebral soft tissue mass

Short curve with severe apical rotation

Intervertebral foraminal enlargement

Widened interpedicular distances

Dysplastic pedicles

NF-1 : neurofibromatosis type-1 
Whole spine radiograph images were reviewed pre-, postoperatively and at 1 year. Those were used to determine coronal and sagittal Cobb angles. The radiographic review for all patients was performed by a spine surgeon who did not involve in this surgical series. All of patients underwent 3-dimensional (3D) computed tomographic (CT) scan to investigate fusion segment, to assess pedicle deformity and bony fusion after surgery. 3D CT was used to confirm bony dystrophic features. The fusion rates were confirmed on CT image at 1 year postoperatively. We also consider loss of correction of $10^{\circ}$ or more as nonunion or pseudarthrosis.

Magnetic resonance imaging also was performed in all patients to confirm dystrophic features such as paraspinal or intraspinal soft tissue mass, dural ectasia and spinal cord compromise (Table 2). To assess preoperative bone quality, BMD by dual-energy X-ray absorptiometry (DEXA) was taken.

For evaluation of clinical outcome, we surveyed the pre- and postoperative scoliosis research society-22r (SRS-22r) score to evaluate pain, function, body image, mental health and satisfaction of patients underwent correction surgery. Surgical details, including approach, levels of the procedure and osteotomy type were examined.

\section{RESULTS}

Seven patients with spinal deformity associated with NF-1 were enrolled in this study. The surgeries were performed via all posterior approach by a single spine neurosurgeon under intraoperative neurophysiologic monitoring. Patients having prior spinal fusion surgeries were excluded. There were fourfemale and three-male patients. The mean age at surgery was $27.7 \pm 1.2$ years old (range, 16-56). The mean follow-up period was $2.8 \pm 1.4$ years with a minimum 1.5 -year follow-up (Table 3 ).

Table 3. Detailed characteristics of the seven patients

\begin{tabular}{lcccccc}
\hline Case & Sex & Age (years) & F/U years & Fusion level & BMD T-score & Osteotomy type \\
\hline 1 & F & 54 & 2 & T9-pelvis & -5.4 & PCO \\
2 & M & 16 & 5 & T3-L1 & -2.8 & PCO \\
\hline 3 & F & 17 & 5 & T4-L3 & -2.3 & PCO \\
\hline 4 & M & 35 & 2 & T10-pelvis & -4.0 & PCO \\
\hline 5 & M & 24 & 2 & T10-pelvis & -2.5 & PCO \\
6 & F & 31 & 2 & T8-L1 & -4.0 & - \\
7 & F & 17 & 1.5 & C2-pelvis & -4.0 & PCO \\
Average & & $27.7 \pm 1.2$ & $2.8 \pm 1.4$ & $11.1 \pm 5.9$ & $-3.5 \pm 1.0$ & \\
\hline
\end{tabular}

F/U : follow-up, BMD : bone mineral density, F : female, PCO : posterior column osteotomy, $\mathrm{M}$ : male

Table 4. Dystrophic characteristics of the seven patients

\begin{tabular}{|c|c|c|c|c|c|c|}
\hline Case & Penciling of ribs & $\begin{array}{l}\text { Scalloping of } \\
\text { vertebrae }\end{array}$ & $\begin{array}{l}\text { Spindling of the } \\
\text { transverse processes }\end{array}$ & $\begin{array}{c}\text { Foraminal } \\
\text { enlargement }\end{array}$ & $\begin{array}{c}\text { Severe rotation of } \\
\text { vertebrae }\end{array}$ & $\begin{array}{c}\text { Adjacent soft tissue } \\
\text { tumor }\end{array}$ \\
\hline 1 & 0 & 3 & 3 & 3 & 0 & No \\
\hline 2 & 3 & 2 & 3 & 0 & 3 & Yes \\
\hline 3 & 4 & 3 & 4 & 3 & 3 & Yes \\
\hline 4 & 0 & 4 & 4 & 3 & 0 & No \\
\hline 5 & 0 & 3 & 0 & 0 & 0 & No \\
\hline 6 & 4 & 4 & 4 & 4 & 4 & No \\
\hline 7 & 0 & 8 & 8 & 6 & 4 & No \\
\hline Average & 1.5 & 3.8 & 3.7 & 2.7 & 2.0 & - \\
\hline
\end{tabular}

The numbers indicate the prevalence of signs in each case 
All patients presented with two or more dystrophic features showed in Table 4 including scalloping of vertebrae and wedging of apical vertebra ${ }^{4,30)}$.

Seven dystrophic curvatures consisted of three thoracic scoliosis, two lumbar scoliosis, one thoracic kyphoscoliosis, one cervicothoracic scoliosis. The kyphoscoliosis means that the degree of kyphosis exceeds $50^{\circ}$. Six patients had one staged procedure by all posterior correction and instrumentation. One patient underwent two staged procedures by anterior release followed by posterior correction and instrumentation.

The preoperative mean coronal Cobb angle and sagittal Cobb angle was $61.6 \pm 22.6^{\circ}$ and $56.8 \pm 18.5^{\circ}$. The postoperative mean coronal Cobb angle and sagittal Cobb angle was $34.6 \pm$ $38.1^{\circ}$ and $40.2 \pm 9.1^{\circ}$. Mean coronal and sagittal correction rate was $44.7 \pm 26.9 \%$ and $23.1 \pm 20.0 \%$ (Table 5). Most patients have poor bone quality with average T-score of $-3.5 \pm 1.0$. At 1 year after surgery, $85.7 \%$ (six of seven) of patients had achieved solid bone fusion. Ultimate follow-up SRS-22r scores (average score, 3.9 \pm 0.4 ) improved comparing to preoperative SRS-22r score (average score, 3.3 \pm 0.9 ) (Fig. 1).

In our series, there were one case of pseudarthrosis (rod fracture) and one case of radiographic loss of correction without clinical symptoms. Only one patient required revision surgery due to symptomatic rod breakage at the lumbosacral area. No serious complication occurred, such as neurologic deficit, viscerovascular injury and deep wound infection.

Table 5. Pre- and postoperative radiologic data

\begin{tabular}{|c|c|c|c|c|c|c|}
\hline Case & $\begin{array}{l}\text { Preop. coronal } \\
\text { Cobb angle }\left({ }^{\circ}\right)\end{array}$ & $\begin{array}{l}\text { Postop. coronal } \\
\text { Cobb angle }\left({ }^{\circ}\right)\end{array}$ & Correction rate (\%) & $\begin{array}{l}\text { Preop. sagittal } \\
\text { Cobb angle }\left({ }^{\circ}\right)\end{array}$ & $\begin{array}{c}\text { Postop. sagittal } \\
\text { Cobb angle }\left({ }^{\circ}\right)\end{array}$ & Correction rate (\%) \\
\hline 1 & 54.9 & 28.6 & 47.9 & 14.0 & 11.1 & 21.0 \\
\hline 2 & 74.5 & 26.9 & 63.8 & 23.2 & 13.9 & 40.0 \\
\hline 3 & 51.8 & 13.8 & 73.3 & 63.7 & 26.6 & 58.2 \\
\hline 4 & 90.3 & 68.5 & 24.1 & 40.0 & 37.8 & 5.0 \\
\hline 5 & 24.0 & 13.4 & 44.1 & 63.6 & 37.8 & 0.7 \\
\hline 6 & 51.2 & 43.2 & 16.2 & 187.7 & 147.7 & 21.3 \\
\hline 7 & 85.0 & 48.0 & 43.5 & 6.0 & 7.0 & 16.0 \\
\hline Mean & $61.6 \pm 22.6$ & $34.6 \pm 38.1$ & $44.7 \pm 26.9$ & $56.8 \pm 18.5$ & $40.2 \pm 9.1$ & $23.1 \pm 20.0$ \\
\hline
\end{tabular}

Preop. : preoperative, Postop. : postoperative

Preop. vs. Postop. SRS-22r

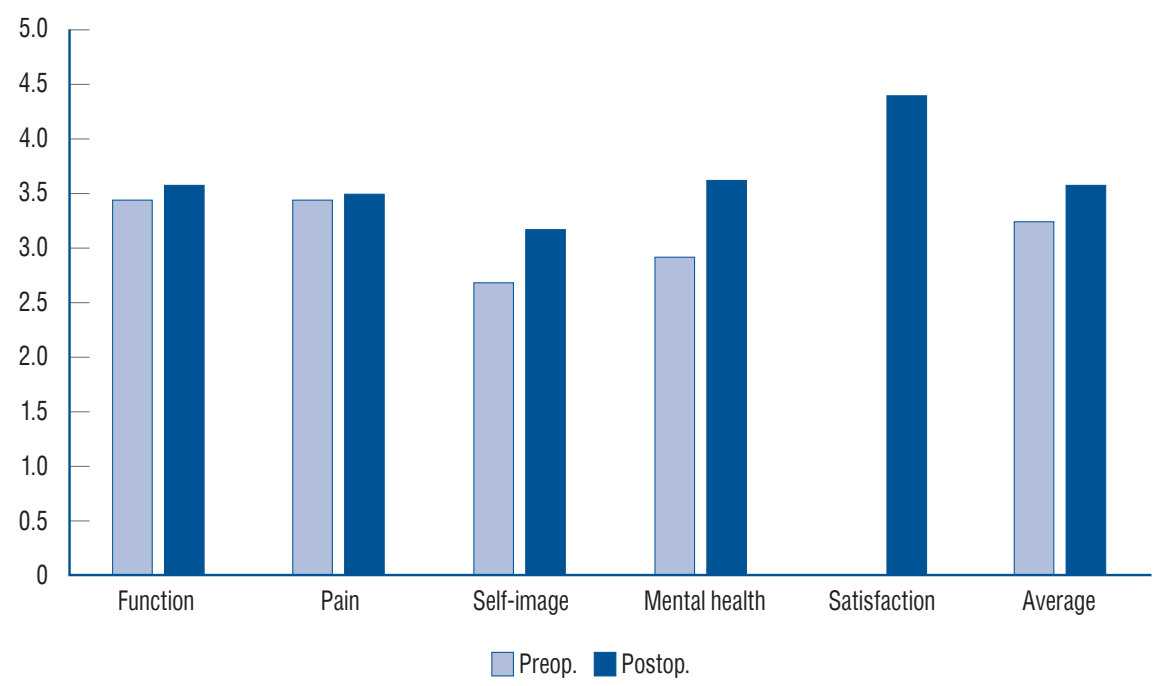

Fig. 1. Pre- and postoperative mean SRS-22r-score of all patients. Preop. : preoperative, Postop. : postoperative, SRS-22r : scoliosis research society-22r. 


\section{DISCUSSION}

In this study, total seven patients with spinal deformity associated with NF-1 were surgically treated by all posterior approach (Fig. 2). The clinical and operative details from previous studies are shown in Table 6. Previous researchers recommended corpectomy and combined circumferential fusion to treat or correct dystrophic scoliosis in NF-1 patients ${ }^{11,14,26)}$. Halmai et al. ${ }^{6}$ reported a series of 12 patients who underwent 3-week preoperative traction and then anterior release, posterior instrumentation and fusion were performed. In these patients, the mean scoliosis correction rate was $66 \%$. There were one neurologic deficit and one pseudarthrosis. Koptan and ElMiligui ${ }^{14}$ reported a series of 32 patients who underwent anterior release followed by posterior hybrid instrumentation augmented by sublaminar wires. The correction rate was $61.8 \%$ and $61 \%$ for scoliotic and kyphotic curves, respectively. Two patients had superficial infection and two patients had a definite pseudarthrosis. Furthermore, one patient experienced a transient weakness in the left lower limb for 3 months. Another investigator reported a series of 16 patients who had undergone anterior and posterior combined fusion ${ }^{26)}$. Surgery improved the mean preoperative scoliosis of $87^{\circ}$ (range, $60^{\circ}-110^{\circ}$ ) and local kyphosis of $69.3^{\circ}$ (range, $50^{\circ}-100^{\circ}$ ) to $49^{\circ}$ (range, $15^{\circ}-85^{\circ}$ ) and $49^{\circ}$ (range, $\left.35^{\circ}-70^{\circ}\right)$, respectively. There were no neurological or wound complications. However, one individual died in the recovery room because of sudden cardiorespiratory arrest apparently from a transfusion. Intraoperative blood loss of $20-25 \%$ of the
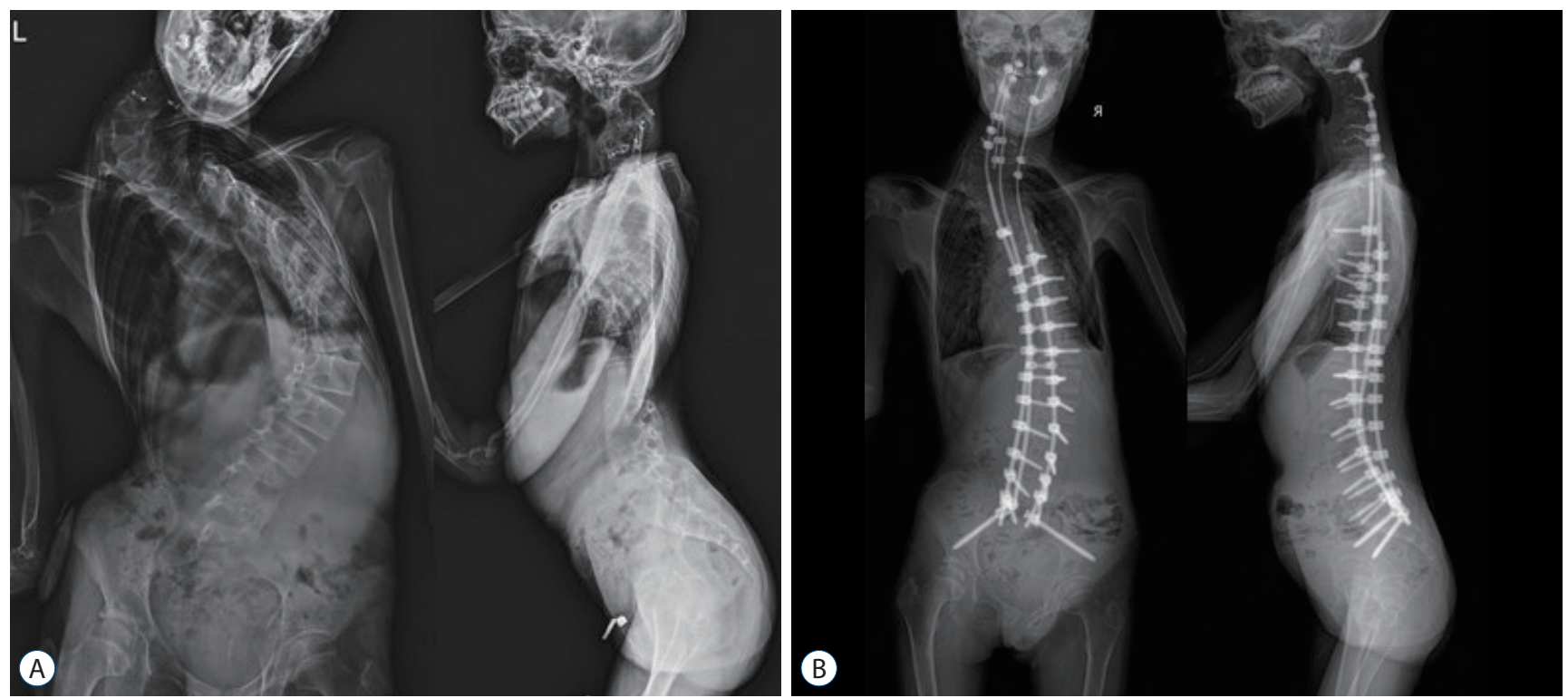

Fig. 2. Preoperative (A) and postoperative (B) plain radiographs of a 17-year old female patient (case No. 7).

Table 6. Clinical and operative details in the literatures of NF-1 deformity or scoliosis

\begin{tabular}{|c|c|c|c|c|c|c|}
\hline Study & Country & No. of cases & Age in years & F/U years & Complications & Surgical approach \\
\hline Halmai et al. ${ }^{6}(2002)$ & Hungary & 12 & 17.5 & 4.4 & $\begin{array}{l}\text { One neurologic deficit } \\
\text { One pseudarthrosis }\end{array}$ & $\begin{array}{l}\text { Anterior release and posterior } \\
\text { instrumentation and fusion }\end{array}$ \\
\hline $\begin{array}{l}\text { Shahcheraghi and } \\
\text { Tavakoli }^{26)}(2010)\end{array}$ & Iran & 9 & 11.8 & 6.7 & $\begin{array}{l}\text { Two surgical site infection } \\
\text { Two pseudarthrosis } \\
\text { One neurologic deficit }\end{array}$ & $\begin{array}{l}\text { Anterior and posterior instrumentation } \\
\text { and fusion }\end{array}$ \\
\hline $\begin{array}{l}\text { Koptan and } \\
\text { EIMiliguili) }^{(2010)}\end{array}$ & Egypt & 32 & 14 & 6.5 & One death & $\begin{array}{l}\text { Anterior release and posterior } \\
\text { instrumentation and fusion }\end{array}$ \\
\hline Wang et al. ${ }^{31)}$ (2015) & China & 16 & 13 & 3.4 & One neurologic deficit & Posterior instrumentation and fusion \\
\hline Deng et al. ${ }^{3)}(2017)$ & China & 31 & 13.5 & 4.4 & One pseudarthrosis & Posterior instrumentation and fusion \\
\hline
\end{tabular}

NF-1 : neurofibromatosis type-1, F/U : follow-up 
total blood volume (including one mortality case) was observed, mainly during the anterior approach.

In recent studies, there are several reports regarding posterior approach to correct spinal deformity associated with NF1. The authors suggested that posterior approach is safe and effective method. Wang et al. ${ }^{31)}$ reported a series of 16 patients who underwent one-stage posterior surgery with pedicle screw system. Mean scoliosis and kyphosis improved from $83.2^{\circ}$ to $27.6^{\circ}$ and $58.5^{\circ}$ to $26.8^{\circ}$, respectively. They found no pseudarthosis or nonunion during follow-up. However, one patient exhibited lower extremity weakness defined as grade 1 muscle strength after surgery. After revision decompression surgery and regular rehabilitation exercises, the patient eventually recovered grade 4 lower extremity muscle strength within 3 months. Another investigator reported a series of 31 patients who underwent posterior only surgical correction using a multiple anchor point method $^{3)}$. The mean postoperative correction rate was $58.7 \%$ (range, $46.3-74.1 \%$ ). Only one patient presented with hook dislodgements because of pseudarthrosis, which required revision surgery. In these two series, the focus is primarily on surgical correction rather than complications that can be caused by the posterior approach. However, in our series, we discussed on how to prevent surgery related complications how to achieve solid bony fusion and how to satisfy the patients' needs. Recently, national trends in spinal fusion surgery for neurofibromatosis in the United States were reported $^{15)}$. The authors analysed 548 patients with a diagnosis of NF-1 who had received spinal fusion surgery be- tween 2003 and 2014. The rate of posterior spinal fusion (PSF) surgeries increased 2.9-fold, whereas the rate of anterior-posterior spinal fusion (APSF) surgeries decreased 2.2-fold. Compared with patients undergoing PSF and anterior spinal fusion, patients undergoing APSF were significantly younger and had significantly higher hospitalization lengths and costs. It is in line with the fact that APSF is an extensive multistage procedure.

For these reasons such as the insufficient anterior bony structure due to dystrophic changes, a high grade of risk of dura injury, and vessel injury, we performed only posterior approach in this series with an acceptable outcome. Moreover, there were no serious complications occurred in the current cohort.

The instrumentation and correction of the deformed curves is not easy due to dystrophic vertebral deformity, pedicle dysplasia and osteoporosis. In addition, in dystrophic scoliosis, very careful exposure is required during surgery due to very thin lamina, and very careful decortication for fusion is needed due to spinal canal injury.

In our series, the preoperative mean coronal Cobb angle and sagittal Cobb angle was $61.6 \pm 22.6^{\circ}$ and $56.8 \pm 18.5^{\circ}$. The postoperative mean coronal Cobb angle and sagittal Cobb angle was $34.6 \pm 38.1^{\circ}$ and $40.2 \pm 9.1^{\circ}$. Mean coronal and sagittal correction rate was $44.7 \pm 26.9 \%$ and $23.1 \pm 20.0 \%$. At 1-year follow-up evaluation, the mean loss of coronal and sagittal correction rate was $2.3 \%$ and $2.4 \%$, respectively.

In our series, a patient underwent revision surgery due to
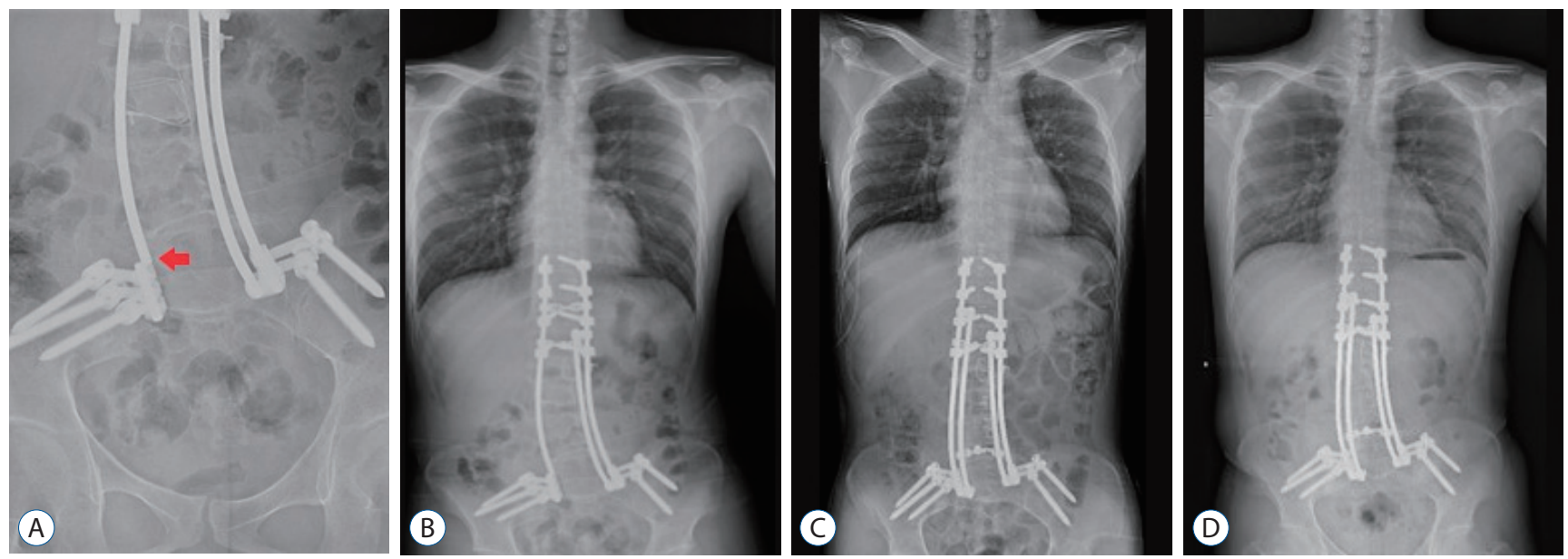

Fig. 3. A and B : Follow-up plain radiographs after initial surgery showing rod fracture (red arrow) above side connector of iliac screw on the right side. C : Postoperative plain radiograph after revision surgery using multiple rod construct by 4-Cobalt Chrome rods. D : Two-year follow-up plain radiograph of a $24-y e a r$ old male patient (case No. 5). 
symptomatic pseudarthrosis with rod fracture (Fig. 3). We revised him using multiple rod construct (multi-RC) and additional posterolateral fusion. Previous broken rod on the right side was replaced by multi-RC using cobalt chrome $(\mathrm{CoCr})$ rod. Patients with conventional 2-rod constructs (2-RC) had a statistically greater incidence of lumbosacral pseudarthrosis than those with multi-rod constructs in adult spinal deformity surgery ${ }^{19)}$. In addition, in another study, there were significant differences in the occurrence of rod breakage and revision surgery for pseudarthrosis at the 3-column osteotomy site (rod breakage, $2-\mathrm{RC}: 11$ vs. multi-RC : $2, p=0.002$; and revision, $2-\mathrm{RC}: 6$ vs. multi-RC $: 0, p=0.011)^{9,16)}$. Thus, the use of a multi-RC is an effective method to provide increased stability to prevent implant failure and symptomatic pseudarthrosis versus a standard 2-RC. It is known to be important that biomechanical properties are dependent on the material of rod. CoCr rod has in recent years been introduced for major spinal deformity surgery, which is characterized by a very high mechanical stiffness ${ }^{7,20)}$.

In several previous studies, a major difficulty encountered in NF-1 patients is the poor bone stock and remarkable osteoporosis which can result in metal failure, hook dislodgement and consequent loss of correction ${ }^{10,30)}$. Furthermore, previous researchers reported that dural ectasia can cause vertebral scalloping and weaken the fixation of the implants which makes loosening of the hooks and loss of correction ${ }^{32)}$. In the case No. 1 patient, there were no the occurrence of proximal junctional kyphosis or proximal junctional failure after surgery $^{8,18,33)}$ (Fig. 4). However, the trunk shift to the left side progressed on the 2-year follow-up radiograph due to loss of correction comparing to the immediate postoperative radiographs. Her pre-/postoperative and 2-year follow-up difference between the vertical trunk reference line (VTRL) and the center sacral vertical line (CSVL) was $50.1 \mathrm{~mm}, 16.6 \mathrm{~mm}$, and 26.3 $\mathrm{mm}$, respectively. According to a previous study, trunk shift was defined as a greater than $2 \mathrm{~cm}$ difference between VTRL and CSVL. They insisted that coronal imbalance does not correlate with trunk shift and undercorrection of the lumbar curve predisposing to the development of postoperative trunk shift $^{29)}$.

In previous studies, most NF-1 patients have significant low $\mathrm{BMD}$ because of defect of bone metabolism ${ }^{22,25)}$. In our series, average T-score of BMD was $-3.5 \pm 1.0$. Five of seven patients had osteoporosis and two patients had osteopenia. Because of the osteoporotic condition in NF-1 patient, the pseudarthrosis rates of patients undergoing surgery have been reported to rise to $60 \%{ }^{27)}$. Thus, we used several strategies to increase fusion rates in these patients ${ }^{1)}$. During surgery, adequate autologous and allogenic bone mixture were used for fusion with meticulously preparing the fusion bed to be decorticated and free
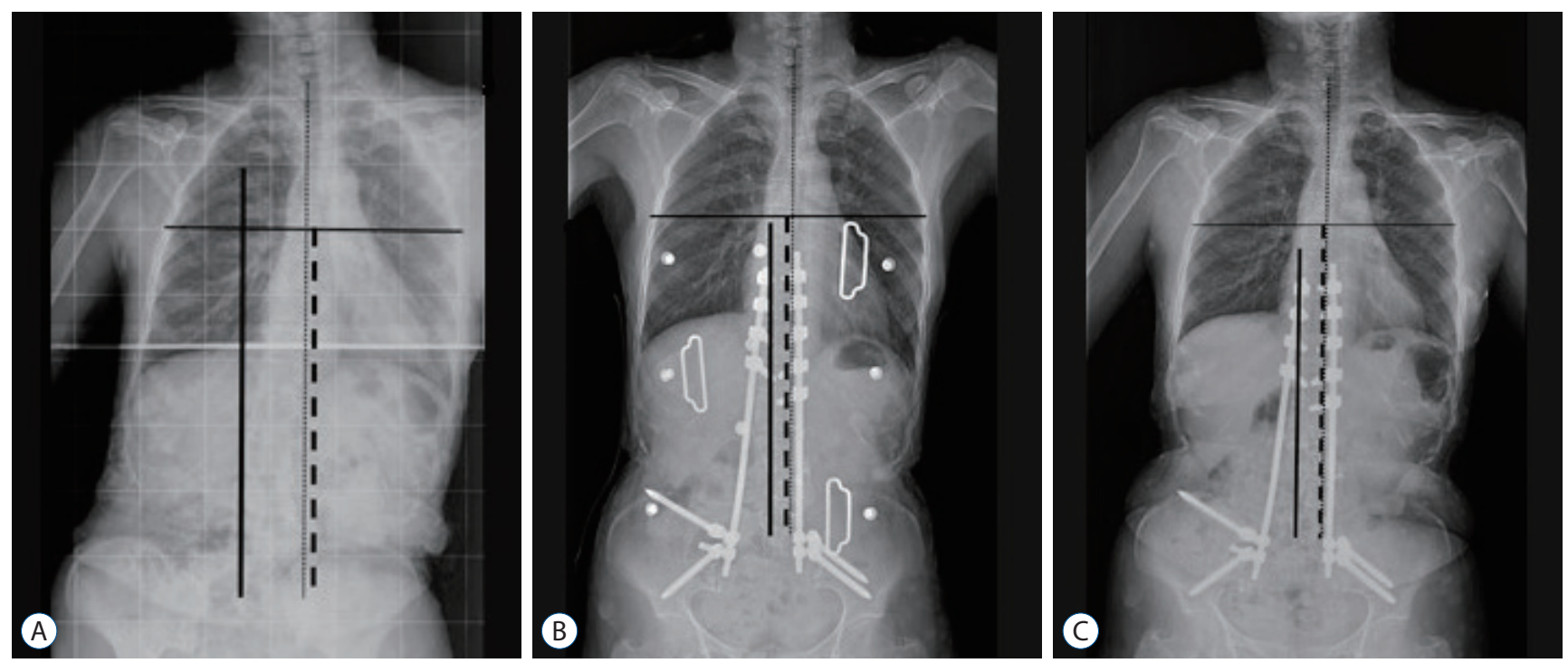

Fig. 4. A : Preoperative whole spine radiograph showing trunk shift to the left side. B: Postoperative plain radiograph revealing improvement of the coronal imbalance. C: Two-year follow-up plain radiograph of a 54-year old female patient (case No. 1). A horizontal line is drawn through the apex of thoracic curve. The bisecting perpendicular line represents the vertical trunk reference line (dashed). The central sacral vertical line (line), and the C7 plumb line (dotted). 
from soft tissue. Furthermore, multiple iliac screws, Wisconsin wires, and multiple-RC technique were utilized to achieve solid bony fusion. These surgical methods may overcome the poor bone quality and compensate for the lack of fixation points caused by pedicle dysplasia ${ }^{13)}$. As a result, in our series, $85.7 \%$ (six of seven) of patients had achieved solid bony fusion on the 1-year follow-up radiographic images.

Finally, we surveyed the pre- and postoperative SRS-22r score to evaluate a satisfaction of all patients underwent correction surgery, Final average SRS-22r score of the patients shows significantly improved than preoperative average score. Considering dystrophic scoliosis in NF-1 patients, we did not focus on the degree of correction in this series. The main purpose of surgery was to prevent progression of deformity, to stabilize the deformed spine and to satisfy the patients' needs.

The limitation of the study is the small number of cases. However, severe spinal deformity associated with NF-1 is a very rare disease entity and the surgical strategy was quite complicated, which is hard to be compared to adolescent idiopathic scoliosis.

\section{CONCLUSION}

The surgical correction of patients having spinal deformity associated with NF-1 is challenging, however, the radiographic and clinical outcomes are satisfactory. All posterior approach can be safe and effective surgical option for patients having dystrophic curves associated with NF-1. The main purpose of this kind of surgery should be focused on stabilizing the deformed spine and stopping the progression of the deformities rather than attempting excessive correction.

\section{CONFLICTS OF INTEREST}

No potential conflict of interest relevant to this article was reported.

\section{INFORMED CONSENT}

This type of study does not require informed consent.

\section{AUTHOR CONTRIBUTIONS}

\author{
Conceptualization : $\mathrm{SJH}$ \\ Data curation : BJP, SHW, JMJ \\ Methodology : BJP, KJK, TAJ \\ Writing - original draft : BJP \\ Writing - review \& editing: SJH, KJK, TAJ
}

\section{ORCID}

Byoung-Joo Park https://orcid.org/0000-0002-4059-5905

Seung-Jae Hyun https://orcid.org/0000-0003-2937-5300

Seong-Hyun Wui https://orcid.org/0000-0001-8811-1589

Jong-Myung Jung https://orcid.org/0000-0002-3718-7740

Ki-Jeong Kim https://orcid.org/0000-0001-8547-8545

Tae-Ahn Jahng https://orcid.org/0000-0001-8342-3874

\section{References}

1. Bae J, Lee $S H$ : Minimally invasive spinal surgery for adult spinal deformity. Neurospine $15: 18-24,2018$

2. Crawford AH : Pitfalls of spinal deformities associated with neurofibromatosis in children. Clin Orthop Relat Res (245) : 29-42, 1989

3. Deng A, Zhang HQ, Tang MX, Liu SH, Wang YX, Gao QL : Posterior-only surgical correction of dystrophic scoliosis in 31 patients with neurofibromatosis type 1 using the multiple anchor point method. J Neurosurg Pediatr 19 : 96-101, 2017

4. Durrani AA, Crawford AH, Chouhdry SN, Saifuddin A, Morley TR : Modulation of spinal deformities in patients with neurofibromatosis type 1. Spine (Phila Pa 1976) $25: 69-75,2000$

5. Elefteriou F, Kolanczyk M, Schindeler A, Viskochil DH, Hock JM, Schorry EK, et al. : Skeletal abnormalities in neurofibromatosis type 1: approaches to therapeutic options. Am J Med Genet A 149A : 2327-2338, 2009

6. Halmai V, Domán I, de Jonge T, Illés T : Surgical treatment of spinal deformities associated with neurofibromatosis type 1. Report of 12 cases. J Neurosurg 97(3 Suppl) : 310-316, 2002

7. Hyun SJ, Jung JM : Spinal deformity surgery : it becomes an essential part of neurosurgery. J Korean Neurosurg Soc 61 : 661-668, 2018

8. Hyun SJ, Lee BH, Park JH, Kim KJ, Jahng TA, Kim HJ : proximal junctional kyphosis and proximal junctional failure following adult spinal deformity surgery. Korean J Spine 14 : 126-132, 2017

9. Hyun SJ, Lenke LG, Kim YC, Koester LA, Blanke KM : Comparison of standard 2-rod constructs to multiple-rod constructs for fixation across 3-column spinal osteotomies. Spine (Phila Pa 1976) 39 : 1899-1904, 2014 
10. Illés $T$, Halmai $V$, de Jonge $T$, Dubousset J : Decreased bone mineral density in neurofibromatosis-1 patients with spinal deformities. Osteoporos Int $12: 823-827,2001$

11. Iwai C, Taneichi H, Inami S, Namikawa T, Takeuchi D, Kato N, et al. : Clinical outcomes of combined anterior and posterior spinal fusion for dystrophic thoracolumbar spinal deformities of neurofibromatosis-1: fate of nonvascularized anterior fibular strut grafts. Spine (Phila Pa 1976) $38:$ 44-50, 2013

12. Kim HW, Weinstein SL: The management of scoliosis in neurofibromatosis. Spine (Phila Pa 1976) 22 : 2770-2776, 1997

13. Kim WB, Park YS, Park JH, Hyun SJ : Posterior spinal reconstruction with pedicle screws, multiple iliac screws and wisconsin spinal wires in a patient with neurofibromatosis scoliosis: a case report. Korean J Spine $12: 181-184,2015$

14. Koptan W, ElMiligui $Y$ : Surgical correction of severe dystrophic neurofibromatosis scoliosis: an experience of 32 cases. Eur Spine J 19 : 15691575, 2010

15. Kurucan E, Bernstein DN, Thirukumaran C, Jain A, Menga EN, Rubery PT, et al. : National trends in spinal fusion surgery for neurofibromatosis. Spine Deform 6 : 712-718, 2018

16. Lee BH, Hyun SJ, Kim KJ, Jahng TA, Kim YJ, Kim HJ : Clinical and radiological outcomes of posterior vertebral column resection for severe spinal deformities. J Korean Neurosurg Soc 61 : 251-257, 2018

17. Lykissas MG, Schorry EK, Crawford AH, Gaines S, Rieley M, Jain VV : Does the presence of dystrophic features in patients with type 1 neurofibromatosis and spinal deformities increase the risk of surgery? Spine (Phila Pa 1976) 38 : 1595-1601, 2013

18. Makhni MC, Shillingford JN, Laratta JL, Hyun SJ, Kim YJ : Restoration of sagittal balance in spinal deformity surgery. J Korean Neurosurg Soc $61: 167-179,2018$

19. Merrill RK, Kim JS, Leven DM, Kim JH, Cho SK : Multi-rod constructs can prevent rod breakage and pseudarthrosis at the lumbosacral junction in adult spinal deformity. Global Spine J 7 : 514-520, 2017

20. Ohrt-Nissen S, Dahl B, Gehrchen M : Choice of rods in surgical treatment of adolescent idiopathic scoliosis: what are the clinical implications of biomechanical properties? - a review of the literature. Neurospine 15 : 123-130, 2018

21. Park YS, Hyun SJ : Spinal deformity in neurofibromatosis: classification and management. J Spine $3: 2,2014$
22. Petramala L, Giustini S, Zinnamosca L, Marinelli C, Colangelo L, Cilenti G, et al. : Bone mineral metabolism in patients with neurofibromatosis type 1 (von Recklingausen disease). Arch Dermatol Res 304 : 325-331, 2012

23. Rezaian SM : The incidence of scoliosis due to neurofibromatosis. Acta Orthop Scand 47 : 534-539, 1976

24. Savini R, Parisini P, Cervellati $S$, Gualdrini $G$ : Surgical treatment of vertebral deformities in neurofibromatosis. Ital J Orthop Traumatol 9 : 1324, 1983

25. Schindeler A, Ramachandran M, Godfrey C, Morse A, McDonald M, Mikulec $\mathrm{K}$, et al. : Modeling bone morphogenetic protein and bisphosphonate combination therapy in wild-type and Nf1 haploinsufficient mice. J Orthop Res $26: 65-74,2008$

26. Shahcheraghi GH, Tavakoli AR : Corpectomy and circumferential spinal fusion in dystrophic neurofibromatous curves. J Child Orthop 4 : 203210, 2010

27. Shen JX, Qiu GX, Wang YP, Zhao Y, Ye QB, Wu ZK : Surgical treatment of scoliosis caused by neurofibromatosis type 1. Chin Med Sci J 20 : 88-92, 2005

28. Sponseller $P$ : The spine in skeletal syndromes and dysplasias in DeWald $\mathrm{RL}$ (ed) : Spinal deformities. The comprehensive text. Thieme : New York, 2003, pp701-717

29. Trobisch PD, Samdani AF, Pahys JM, Cahill PJ : Postoperative trunk shift in Lenke 1 and 2 curves: how common is it? and analysis of risk factors. Eur Spine J 20 : 1137-1140, 2011

30. Tsirikos Al, Saifuddin A, Noordeen MH : Spinal deformity in neurofibromatosis type-1: diagnosis and treatment. Eur Spine J 14 : 427-439, 2005

31. Wang Z, Fu C, Leng J, Qu Z, Xu F, Liu Y : Treatment of dystrophic scoliosis in neurofibromatosis type 1 with one-stage posterior pedicle screw technique. Spine J 15 : 587-595, 2015

32. Winter $R B$, Anderson $M B$ : Spinal arthrodesis for spinal deformity using posterior instrumentation and sublaminar wiring. A preliminary report of 100 consecutive cases. Int Orthop 9 : 239-245, 1985

33. Wui SH, Hyun SJ, Kang B, Kim KJ, Jahng TA, Kim HJ : Bicortical screw purchase at upper instrumented vertebra (UIV) can cause uiv fracture after adult spinal deformity surgery: a finite element analysis study. Neurospine $17:$ 377-383, 2020

34. Neurofibromatosis. Conference statement. National Institutes of Health Consensus Development Conference. Arch Neurol 45 : 575-578, 1988 